\title{
O custo salarial da duração do desemprego para o trabalhador
}

\author{
Paulo Aguiar do Monte \\ Professor da Universidade Federal da Paraiba \\ Ignácio Tavares de Araújo Júnior \\ Professor da Universidade Federal da Paraiba \\ Márcia de Lima Pereira \\ Professora da Universidade Federal de Campina Grande
}

\section{Palauras-chave}

desemprego, reinserção ocupacional, salário, salário de reserva.

Classificação JEL J20, J30, $\mathrm{J} 64$.

Key words

unemployment, occupational reinsertion, wage, reservation wage.

JEL Classification J20, J30, J64.

\section{Resumo}

Este trabalho tem como objetivo analisar a influência do tempo de desemprego na reinserção ocupacional; mais especificamente, no salário auferido pelo trabalhador que conseguiu transitar da situação de desempregado para a de ocupado no segmento formal da economia. Tendo como amostra os microdados da Pesquisa Mensal de Emprego (2000) e utilizando a técnica de regressões quantílicas, o trabalho fornece evidências sobre a perda salarial provocada pela duração do período em que esteve desempregado. Os resultados indicaram chances heterogêneas de permanência no estado de desemprego, quase sempre em favor dos indivíduos menos qualificados, assim como foram constatadas perdas salariais quando do reingresso ocupacional. Ademais, de forma geral, os indivíduos com segundo grau ou nível superior de escolaridade são os mais penalizados, não importando o quantil onde estejam na distribuição condicional dos salários, indicando, portanto, maior perda para os empregados nos postos de trabalho que exigem maior qualificação.

\section{Abstract}

This paper analyzes the influence of unemployment on occupational reinsertion, specifically on the wage earned by the workers who transitioned from unemployment to being employed.

Using sample data from Monthly Employment Survey (PME, 2000), from Brazil, and quantile regression techniques, this study provides evidence about the relationship between duration of unemployment and wage loss. The results show a heterogeneous chance to remain unemployed, in favor, mainly, of less qualified workers, and, in addition, wage losses are observed when the employed find a new job (occupational reinsertion).

Moreover, in general, workers who have more qualification are more penalized, regardless of the quantile conditional wage distribution they are in, indicating a greater loss for employees in jobs that require higher qualification. 


\section{1_Introdução}

Durante as últimas décadas, o Brasil tem convivido com taxas elevadíssimas de desemprego que chegaram a níveis poucas vezes alcançados em sua história. Sabe-se que diversos fatores contribuíram para esse cenário, entre os quais, o baixo crescimento econômico observado nos últimos trinta anos (em termos médios, menos de 3,0\% ao ano), que pode ser considerado um dos mais importantes, senão o maior deles.

Não obstante a elevação das taxas médias de desemprego, também se verificou o aumento da sua duração, fato que se observou tanto no contexto internacional (Mukoyama e Sain, 1994; Oison, 1995) quanto nacional, particularmente a partir dos anos noventa. $\mathrm{O}$ aumento da duração do desemprego deteriora, ainda mais, a situação do trabalhador no mercado de trabalho (Decker e Levine, 2001), tendo reflexo direto na sua inserção ocupacional. Ademais, é necessário ressaltar que a duração do desemprego varia entre os diferentes grupos da força de trabalho, sendo, portanto, mais grave para determinadas classes populacionais. De forma geral, para os indivíduos menos escolarizados, a permanência no estado de desemprego é menor em relação aos mais escolarizados, e um dos fatores determinantes nessa questão é o salário de reserva do trabalhador. (Roed, Raaum e
Goldstein, 1999; Menezes Filho e Picchetti, 2002; Malbouisson e Menezes, 2004; Addison, et al., 2008).

A literatura econômica não estabelece, a priori, o sinal da relação entre taxa de desemprego e duração do desemprego. Caso determinado segmento da população apresente uma elevada taxa de desemprego, esse indicador não está necessariamente condicionado a uma menor probabilidade de inserção ocupacional, em virtude da rotatividade existente no mercado de trabalho (Clark e Summers, 1992). Logo, a relação entre ambas não é tão direta quanto possa parecer.

Neste estudo, parte-se da premissa de que o tempo de permanência no desemprego afeta o salário futuro do trabalhador, dado que uma permanência maior no desemprego pode refletir em custos adicionais, tanto para o demandante quanto para o ofertante de mão de obra. Assim, para o demandante, o maior tempo que o indivíduo passar desempregado poderá ser visto como uma indicação negativa de sua produtividade, já que a ausência na ocupação de determinada atividade por um longo período refletirá em um trabalhador inapto, no momento, para a execução de uma atividade específica. Isso acarreta um custo adicional de treinamento (que as empresas podem não estar dispostas a fazer) 
1 RMR (Região

Metropolitana do Recife), RMSA (Região Metropolitana de Salvador), RMRJ (Região

Metropolitana do Rio de Janeiro), RMBH (Região

Metropolitana de Belo Horizonte), RMSP (Região Metropolitana de São Paulo) e RMPA (Região Metropolitana de Porto Alegre). para reinseri-lo numa ocupação. Pissarides (1992) e Blanchard e Diamond (1994) destacam que, de maneira geral, as decisões de contratação das firmas são feitas com base no trabalhador que se encontra desempregado há pouco tempo, visto que se assume haver deterioração das habilidades dos trabalhadores com a duração do desemprego.

Para o ofertante, maior tempo de desempregado pode acarretar em maiores custos de procura, do ponto de vista financeiro e psicológico, além da perda de capital humano (skills). Para Ljungqvist e Sargent (1997) e Den Hann, Haefke e Ramey (2001), o longo período de desemprego gera perdas de habilidades para o trabalhador, dificultando seu reingresso ocupacional, e, con- sequentemente, contribuindo para o aumento das taxas de desemprego. É verdade também que a permanência no estado de desemprego pode ser uma opção do trabalhador em busca de melhores empregos, visto que as oportunidades de trabalho disponíveis em certo momento podem não ser consideradas atrativas, condizentes com as suas expectativas profissionais e pessoais; no entanto, deve-se estar consciente que essa busca não pode ser indeterminada ao longo do tempo.

Nesse contexto, discutir a transição do desemprego para o emprego e as variáve is que afetam o salário do trabalhador recémocupado - entre as quais merece destaque a influência do tempo que o trabalhador permaneceu procurando emprego - constituise o principal objetivo deste artigo. Para tal, inicialmente, será realizada uma comparação entre o salário dos recém- ocupados (ou os que estavam desempregados e conseguiram um trabalho) e o dos indivíduos que não estiveram desempregados, tendo como base os microdados da Pesquisa Mensal de Emprego (2000), de seis regiões metropolitanas do Brasil (RMR, RMSA, RMBH, RMRJ, RMSP e RMPA). ${ }^{1}$ Posteriormente, empregando-se o método de estimação para regressões quantilicas, busca-se verificar se os efeitos do tempo que o trabalhador permaneceu desempregado possuem implicações diferentes sobre o seu rendimento, conforme caminhemos pelos quantis da distribuição condicional do salário.

Afora esta introdução, o artigo é composto de mais seis seções. A seção dois é dedicada à abordagem teórica dos principais fundamentos da oferta de trabalho e da determinação salarial. A terceira seção reporta-se às considerações de ordem metodológica (procedimentos econométricos para estimar a influência da duração do desemprego sobre o salário do trabalhador e os relativos à seleção da amostra). Nas seções 4 e 5 , são analisados os resultados empíricos das análises descritiva e econométrica. Por fim, a última seção trata das considerações finais. 


\section{2_Aportes teóricos da oferta de trabalho e da determinação salarial}

O modelo neoclássico da oferta de trabalho, em sua concepção original, é basicamente restrito ao uso de variáveis que afetam a escolha entre trabalho (b) e lazer (l). A análise parte da premissa de que a busca pelo emprego constitui, em última instância, uma decisão do indivíduo sobre como alocar seu tempo entre trabalho e lazer, tendo por base uma função utilidade individual $(U)$, cujos argumentos são uma cesta de consumo $(x)$ e a quantidade de tempo dedicada ao lazer.

Ao disponibilizar parte do seu tempo diário ao trabalho, o indivíduo recebe uma renda proveniente do seu esforço salário (w), definido pelo produto entre a taxa de salário e o número de horas trabalhadas $(w \cdot h)$ - da qual esse se utiliza para adquirir sua cesta de consumo, auferida pela renda do trabalho ou do não trabalho $(y) .^{2}$

Assim, o indivíduo se defronta com o problema de maximização de utilidade sujeita a sua restrição orçamentária, que pode ser descrito da seguinte forma:

$\operatorname{Max} U=U(x, l)$

s.a. p. $x \leq y+w . h$
De acordo com as hipóteses do modelo, tanto o preço da cesta de consumo ( $p$ ) quanto o preço de seu trabalho (w) são consideradas variáveis exógenas; logo, o indivíduo não tem poder de determiná-los. Sendo assim, resta-lhe fazer uma escolha entre horas de lazer e horas de trabalho, dado que o consumo $(x)$ é determinado pelas horas de trabalho (b) vezes o salário (w) - exógeno.

Mais recentemente, Pencavel (1986) fez uma apreciação do modelo neoclássico da oferta de trabalho, considerando que o nível de utilidade individual depende não apenas da quantidade de horas de lazer ou de trabalho, por período, mas também de outras variáveis, como os atributos pessoais do indivíduo $(A)$ e determinadas características não observáveis $(\varepsilon)$. Assim, o autor descreveu a seguinte função utilidade:

$U=U(x, b ; A, \varepsilon)$

Portanto, cabe ao indivíduo determinar a quantidade de bens que deseja adquirir $(x>0)$ e o número de horas de trabalho $(h>0)$ que maximize sua utilidade, sujeito à restrição orçamentária acima especificada (1). Maximizando a função utilidade (2), tem-se como condição de primeira ordem:

$$
\text { (1) } \frac{w}{p}=-m(x, h: A, \varepsilon)=-\frac{\partial U / \partial h}{\partial U / \partial x}
$$

\footnotetext{
Borjas (1996) afirma que transferência de recursos do Estado para o indivíduo consiste numa espécie de renda do não trabalho, que altera a restrição orçamentária do indivíduo, fazendo com que ele prefira menos emprego e mais lazer.
} 
Esse resultado mostra que o salário real $(w / p)$ pode ser interpretado como o preço (custo) que o indivíduo ou a família paga pelo lazer. Assim, o indivíduo maximiza sua utilidade, escolhendo uma quantidade de bens e horas de trabalho de forma que o sinal negativo da taxa marginal de substituição de horas de trabalho por bens (m) seja igual ao salário real $(w / p)$. As funções de demanda por bens e oferta de trabalho derivadas por meio da resolução das equações (1) e (2) são:

$$
\begin{aligned}
& x=x(p, w, y: A, \varepsilon) \\
& b=x(p, w, y: A, \varepsilon) \text { se } b>0
\end{aligned}
$$

Essa mesma solução pode ser obtida com o uso do conceito de "salário de reserva" $\left(w^{*}\right)$, assumindo, neste artigo, o salário de reserva como o nível de salário a partir do qual o trabalhador aceita traba-

\footnotetext{
3 Borjas (1996) cita como

determinantes do salário de reserva a própria escolha do indivíduo e as rendas oriundas de outras fontes que não o trabalho.

4 Tanto no contexto nacional quanto internacional, existem vários estudos sobre a eficiência econômica das Políticas Públicas no mercado de trabalho, entre as quais os Programas de Reposição de
}

lhar. Segundo a teoria neoclássica da oferta de mão de obra, qualquer variável que seja capaz de elevar o salário de reserva do indivíduo fará com que ele passe a disponibilizar menos horas ao trabalho, e com isso mais horas ao lazer. $^{3}$ As equações 5 e 6 mostram que, se o salário de mercado excede o salário de reserva, o indivíduo decide participar (ativamente) do mercado de trabalho e ofertar um número positivo de horas de trabalho; caso contrário, todo o seu tempo será dedicado ao lazer.

$$
\begin{aligned}
& \text { se } w>w^{*}, b=x(p, w, y: A, \varepsilon)>0 \\
& \text { se } w<w^{*}, b=0
\end{aligned}
$$

Dado que haverá um nível de salário abaixo do qual o indivíduo não participará do mercado de trabalho, é factível supor que, quanto maior for o valor que o indivíduo atribui ao lazer ou o montante das rendas do não trabalho recebidas ou a sua capacidade produtiva, maior será o seu salário de reserva. Cabe ressaltar que a discussão sobre as variáveis que interferem no salário de reserva é bastante complexa, ultrapassando os limites das discussões acadêmicas ou teóricas e serve de balizamento para a formulação de Políticas Públicas. ${ }^{4}$

A partir dos anos sessenta, um novo arcabouço teórico foi desenvolvido, apoiado no modelo neoclássico da oferta de tra- 
balho, com a incorporação de variáveis relacionadas à informação do mercado de trabalho. Esse novo modelo, chamado na literatura de Theory of Job Search, tornou-se uma ferramenta importante para se compreender o funcionamento do mercado de trabalho. As teorias que enfatizavam a questão da procura por emprego ganharam mais difusão nas análises do desemprego, embora se saiba que o fenômeno do desemprego está relacionado diretamente à oferta de trabalho e à inserção ocupacional. ${ }^{5}$

De forma geral, as teorias da procura por emprego (Theory of Job Search) consideram que o indivíduo que está procurando um emprego não conhece todas as oportunidades disponíveis e sua respectiva remuneração. Essa escassez de informação acerca do mercado de trabalho resulta em custos econômicos gerados pelo esforço da procura por emprego, que perduram até que se encontre uma ocupação. Ao encontrar uma oportunidade, o indivíduo passa pelo dilema entre aceitar a oferta de emprego ou continuar procurando outra que seja compatível com suas expectativas profissionais, ou seja, com o seu nível de qualificação e seu salário reserva.

Nesse processo de escolha, o indivíduo leva em consideração os benefícios de prolongar sua procura pelo emprego (melhor proposta, possibilidade de se qualifi- car mais) e os custos dessa procura (financeiro - transporte, compra de jornais - e o de oportunidade - deixando de ganhar algum dinheiro em outro emprego para continuar procurando um melhor emprego). Assim, as teorias da procura por emprego afirmam que a duração do desemprego interfere na decisão do indivíduo de procurar um emprego e no esforço de sua procura, afetando assim a oferta de trabalho.

As consequências da duração do desemprego sobre o salário do trabalhador ainda são pouco discutidas na literatura econômica nacional. No entanto, merecem destaque os trabalhos de Menezes Filho e Pichetti (2002), Zylberstajn e Balbinotto Neto (2002) e Oliveira e Carvalho (2006). Os dois primeiros focalizam suas análises nos determinantes da duração do desemprego, voltando-se, sobretudo, para investigar a influência das características pessoais dos indivíduos no tempo de permanência no desemprego, enquanto o trabalho de Oliveira e Carvalho (2006) se distingue por relacionar esse fenômeno ao salário de reserva dos trabalhadores; além disso, retrata a intensidade da duração do desemprego.

Quando se trata de estudos empíricos que acompanham os indivíduos desde o momento em que esses ingressaram no desemprego até o momento em que são (re)inseridos em alguma atividade, ou seja,
5 Uma hipótese assumida na Teoria Job Search fundamenta-se no fato de que os indivíduos que buscam emprego maximizam seu bem-estar com o valor presente da expectativa futura de renda líquida. A renda líquida futura é dada pela subtração da renda do não trabalho (obtida em trabalhos anteriores e pelos benefícios recebidos do desemprego) pelos custos de procura por trabalho (dado que os trabalhadores, ao realizarem esforço de procura por emprego, incorrem em custos financeiros/psicológicos). Assim, o indivíduo espera obter no futuro uma renda líquida menor do que a renda líquida no presente. 
a duração completa do desemprego, bem como o salário que esses passam a receber no mercado de trabalho, a literatura nacional mostra-se relativamente carente, sendo necessário recorrer aos artigos internacionais. Nesses termos, Addison e Portugal (1989), através de uma estimação por mínimos quadrados ordinários, concluíram que mais períodos de duração no desemprego acarretam uma queda no salário auferido. Fato similar foi encontrado por Gregory e Jukes (2001), que verificaram o efeito da incidência e da duração de desemprego nos salários dos homens britânicos, no período de 19841994. Os autores também constataram que, à medida que o tempo de permanência do indivíduo aumentava, declinava seu salário de reinserção.

Segundo Pissarides (1992), a distribuição dos salários oferecidos ao trabalhador sofre um deslocamento ao longo do tempo, causando, assim, redução do seu salário de reserva e, portanto, no salário esperado de seu novo emprego. Por sua vez, Knight e Li (2006) abordam essa questão partindo da suposição de existência de uma relação negativa entre tempo de duração efetiva do desemprego e os salários recebidos no reemprego. Os autores têm como fundamento quatro hipóteses, a saber: 1) Com o passar do tempo, o salário de reserva pode cair como reflexo da redução no grau de apoio de família, amigos ou benefício de desemprego; 2) Possibilidade de queda do capital humano por obsolescência ou falta de uso, tendendo a diminuir o salário como resposta a uma elevação de desemprego; 3) O mercado de trabalho, para o desempregado, pode ficar excessivamente mais rígido à medida que o tempo passa, reduzindo o salário de reserva. 4) Dado que os empregadores estão sempre em busca do trabalhador mais produtivo, acredita-se que, com a duração do desemprego, os que permaneceram desempregados possuem qualidade inferior, sendo obrigados a baixar os salários de reserva caso queiram um novo emprego.

\section{3_Considerações metodológicas e base de dados}

Inicialmente neste estudo, o potencial efeito do tempo de desemprego sobre o salário será investigado comparando-se o salário médio dos indivíduos recém-empregados (ou que estavam desempregados e conseguiram se inserir no mercado de trabalho) com o salário médio dos indivíduos que não experimentaram a situação de desemprego. Caso o salário médio deste segundo grupo de indivíduos seja superior ao do primeiro e se a diferença entre as médias for estatisticamente significativa, 
então há indício de que o fato de o indivíduo ficar por algum tempo desempregado pode ocasionar perdas salariais futuras.

Todavia, esse diferencial de salário pode acontecer em razão de os trabalhadores considerados neste estudo possuírem diferentes atributos pessoais que também afetam sua remuneração, tais como gênero, idade e escolaridade. Portanto, numa segunda etapa, será realizada uma análise condicionada, levando-se em conta características dos membros da amostra que explicam uma parcela importante de seus rendimentos.

Estimando-se a equação (7), através do método dos mínimos quadrados ordinários, pretende-se captar os efeitos do desemprego sobre os salários dos recém-empregados, considerando os atributos pessoais dos trabalhadores,

$w=X \beta+\gamma D+\varepsilon$

Em que $w$ indica o salário ganho por hora trabalhada de indivíduos que ficaram desempregados por algum período de tempo e que conseguiram um emprego em seguida e de indivíduos que não ficaram desempregados. A variável $X$ indica um vetor com as características desses indivíduos, incluindo idade, gênero, condição na família, nível de escolaridade e região onde reside. A variável idade é representada por variáveis dummies para quatro faixas etárias, a saber: $\mathrm{I}_{1}$ (até 20 anos), $\mathrm{I}_{2}$ (21 a 24 anos), $\mathrm{I}_{3}$ (de 25 a 30 anos) e I (de 31 a 40 anos), sendo o grupo com idade entre 41 a 65 anos utilizado como base. O gênero é captado mediante uma dummy cujo valor é 1 (um), se o indivíduo é do gênero masculino, e 0 (zero), se o indivíduo é do gênero feminino. A condição na familia é levada em conta adotando-se a seguinte taxonomia: $\mathrm{C}_{1}$ (chefe de família), $\mathrm{C}_{2}$ (fillho) e $\mathrm{C}_{3}$ (cônjuge), sendo a categoria outros (categoria que inclui outro parente, agregado, pensionista, empregado doméstico e parente do empregado doméstico) usada como referência. Os setores de atividade econômica foram organizados em três grupos: setor primário $\left(\mathrm{S}_{1}\right)$, setor secundário $\left(\mathrm{S}_{2}\right)$ e setor terciário $\left(\mathrm{S}_{3}\right)$, sendo este último omitido nas regressões e utilizado como base de comparação para os demais. O nível de escolaridade apresenta as seguintes variáveis indicadoras: $\mathrm{E}_{1}$ (primeiro grau incompleto), $\mathrm{E}_{2}$ (primeiro grau completo), $\mathrm{E}_{3}$ (segundo grau incompleto), $\mathrm{E}_{4}$ (segundo grau completo) e $\mathrm{E}_{5}$ (superior), com a categoria escolaridade analfabeto sendo usada como base. ${ }^{6}$ Por fim, levou-se em conta também a região metropolitana onde o indivíduo reside, especificando dummies para as Regiões Metropolitanas de Recife, Salvador, Belo Horizonte, Rio de Janeiro e Porto Alegre. A Região Metropolitana de São Paulo foi considerada como base para interpretação dos resultados.

\footnotetext{
Salienta-se que uma determinada classe de escolaridade não significa um nível pleno dessa escolaridade, visto que alguns indivíduos não concluíram os respectivos cursos de primeiro grau, segundo grau e superior.
} 

do desemprego estimada pelo IBGE refere-se à duração interrompida das ocorrências de desemprego - a qual pode se dar via saída da força de trabalho ou obtenção do emprego. A informação coletada, portanto, diz respeito à duração do desemprego em curso, já que, no momento em que é registrada, a ocorrência do desemprego ainda não chegou necessariamente ao seu fim.
A variável $D$ é uma dummy que assume o valor 1 quando o indivíduo passou algum tempo desempregado antes de assumir seu posto de trabalho atual. Caso a estimativa do parâmetro $\gamma$ apresente sinal negativo e seja estatisticamente significante, constata-se que um indivíduo recém-empregado recebe um salário inferior ao de outro que não ficou desempregado e que possui as mesmas características do primeiro (gênero, idade, escolaridade, condição na família e região metropolitana onde reside).

Embora possibilite uma evidenciação empírica mais rigorosa do que a simples comparação de médias, a estimação da equação 7 não informa se os salários recebidos pelos recém-contratados são afetados pela duração do desemprego, não permitindo corroborar, por exemplo, a relação negativa entre tempo de desemprego e salário no reemprego, constatada por Knight e Li (2006). A relação entre o salário e a duração do desemprego é investigada na equação 8 a seguir:

$w=X \beta+\delta D \cdot T+\mu$

Onde X é o mesmo vetor de características individuais levadas em conta na equação 7 , e o termo D.T é uma interação da dummy que indica se o indivíduo estava desempregado com o tempo de desemprego desse indivíduo (T). A variável tempo de desemprego corresponde à duração completa do tempo de permanência no estado de desemprego, ou seja, representa o período no qual o indivíduo ficou desempregado até reingressar ao mercado de trabalho. O termo $\mu$ é uma perturbação estocástica. ${ }^{7}$

Como destacaram Oliveira e Carvalho (2006), o nivel educacional é uma variável relevante na explicação da duração do desemprego. Partindo-se, porém, da hipótese de que o tempo de desemprego afeta de forma distinta indivíduos com diferentes características, os resultados obtidos na estimação da equação 8 não informam como a duração do desemprego penaliza o salários de trabalhadores com diferentes níveis de escolaridade. Estimando-se a equação 9, procura-se esclarecer essa dúvida:

$w=X \beta+\sum_{i=1}^{5} \rho_{i} D E_{i} \cdot T+\mu$

Em que o termo $D E$. T é uma interação entre as dummies dos 5 níveis educacionais considerados e o tempo de desemprego.

As equações 7, 8 e 9 serão estimadas utilizando-se o método de mínimos quadrados ordinários, ou seja, os parâmetros serão estimados na média da distribuição condicional de salários. Buscando explorar outra dimensão na relação entre salários e duração de desemprego, serão estimadas 
também regressões em diferentes quantis da distribuição condicional dos salários. $\mathrm{Na}$ medida em que pessoas situadas em diferentes quantis da distribuição condicional do salário são indivíduos supostamente com patamares distintos de produtividade ou habilidades produtivas ou, até mesmo, diferentes salários de reserva, espera-se que a duração do desemprego tenha efeitos diferenciados conforme seja o patamar de salário do trabalhador. Dessa forma, empregando-se o método de estimação para regressões quantílicas, será verificado se os efeitos da duração do desemprego possuem implicações diferentes sobre os rendimentos dos trabalhadores, conforme caminhemos pelos quantis da distribuição condicional do salário.

Basicamente, as regressões quantilicas respondem à seguinte pergunta: quais seriam as estimativas dos parâmetros de uma equação em um determinado quantil $\theta$ da distribuição condicional da variável dependente? Segundo Koencker (2005), a resposta que as regressões quantilicas fornecem é um vetor de estimativas dos parâmetros da equação para cada quantil da distribuição condicional da variável dependente. ${ }^{8}$

Por meio dessa técnica de estimação, serão obtidos vetores com estimativas dos parâmetros da equação 10 nos quantis $\theta=\{0,10 ; 0,25 ; 0,50 ; 0,75 ; 0,90\}$, da distribuição condicional do salário.
$Q_{\theta}(w \mid X)=X \beta_{\theta}+\delta_{\theta} D \cdot T+\mu$

Na qual $\beta_{\theta}$ e $\delta_{\theta}$ representam os vetores de parâmetros estimados para cada um dos quantis: $\theta=\{0.10,0.25,0.50,0.75,0.90\}$, da distribuição condicional dos rendimentos.

Por fim, um novo exame empírico será conduzido com o objetivo de investigar os possíveis efeitos do tempo de desemprego sobre o salário do trabalhador em diferentes quantis da distribuição condicional de salários conforme o nível educacional, como indicarão os resultados da estimação da equação 11, abaixo:

$Q_{\theta}(w \mid X)=X \beta_{\theta}+\sum_{i=1}^{5} \rho_{i \theta} D E_{i} \cdot T+\mu$

Os parâmetros $\rho_{i \theta}$ indicarão o efeito da duração do desemprego sobre o salário no quantil $\theta$ da distribuição condicional para os indivíduos com nível educacional $i$.

\section{Base de Dados}

A base de dados foi construída valendose das informações primárias contidas nos arquivos da Pesquisa Mensal de Emprego, do ano 2000, para as 6 regiões metropolitanas cobertas pela Pesquisa (RMR, RMSA, RMBH, RMRJ, RMSP e RMPA).

Dada a periodicidade mensal da Pesquisa (a PME segue um esquema de rotação de painéis, onde cada indivíduo é en-

\footnotetext{
8 Mais detalhes sobre as técnicas de regressão quantílica podem ser encontradas em Koencker e Basset (1978).

9 A mudança metodológica ocorrida na PME, a partir de 2003 , impede que a mesma metodologia aplicada neste trabalho possa ser utilizada em períodos mais recentes.
} 
$\cdots \cdots \cdots \cdots$

10 A partir de 2003, com a mudança metodológica da PME, a informação sobre o tempo de duração do desemprego não é mais contínua, passando a ser informada através de períodos de tempo. trevistado por quatro meses consecutivos, excluído da amostra por oito meses e novamente reinserido por mais quatro meses seguidos, quando é definitivamente retirado da amostra), foi possível selecionar a base de dados mediante o acompanhamento dos indivíduos ao longo do período do estudo.

Para atingir o objetivo, diversas amostras foram criadas, mas a principal delas contém em um banco de dados todos os indivíduos que responderam à pesquisa os quatro meses consecutivos e que, no primeiro mês $(t=1)$, estavam na condição de desocupado. Com essa metodologia, será possível observar sua provável transição para a situação de ocupado ou inativo, ou permanência na situação de desempregado no último mês (tempo $t=4$ ).

As análises estarão restritas ao ano de 2000, em que, através das informações contidas na PME, é possível obter dados mais precisos do tempo efetivo - duração completa - que o trabalhador ficou desempregado até alcançar o emprego. ${ }^{10}$ Somente por meio desse procedimento será possível obter o salário, nominal por hora trabalhada do recém-empregado e analisar as variáveis que interferiram em sua determinação, entre as quais, o tempo de permanência no estado de desemprego.

\section{Análise descritiva das consequências do tempo de desemprego na inserção ocupacional do trabalho}

Tendo como base a amostra de indivíduos que foram acompanhados durante os 4 meses contínuos da entrevista, é possível fazer uma análise de transição da situação do indivíduo ao longo desse período. Seguindo tal metodologia, a amostra foi formada por 7.899 indivíduos (48,9\% homens e $51,1 \%$ mulheres), distribuída nas seguintes regiões: RMSA (1.380), RMBH (1.746), RMR (1.073), RMRJ (943), RMSP (1.586) e RMPA (1.171).

Considerando que todos os indivíduos encontravam-se na situação de desocupados (no tempo $t=1$ ), observou-se que $37,9 \%$ (2.990) conseguiram transitar para a situação de ocupados, $17,5 \%$ (1.379) tornaram-se inativos, e 44,7\% (3.530) permaneceram desocupados. As informações estão contidas na Tabela 1, que retrata o percentual de indivíduos ocupados, desocupados e inativos (no tempo $t=4$ ) e seu respectivo tempo de duração de desemprego observado. Nessa tabela, é possível perceber que a RMSA apresentou o maior percentual de ocupados (50,0\%), cabendo à RMRJ e à RMBH os maiores índices de desocupados e de inativos (51,5 e 24,7\%, respectivamente). 
Tabela 1_ Percentual de indivíduos desocupados no tempo $t=1$ segundo sua situação no mercado de trabalho e tempo de desemprego (em meses), observado no tempo $t=4$, por região metropolitana do Brasil -2000

\begin{tabular}{|c|c|c|c|c|c|c|}
\hline \multirow{3}{*}{ Região } & \multicolumn{6}{|c|}{ Situação no tempo $t=4$} \\
\hline & \multicolumn{2}{|c|}{ Ocupado } & \multicolumn{2}{|c|}{ Desocupado } & \multicolumn{2}{|c|}{ Inativo } \\
\hline & $\%$ & Tempo & $\%$ & Tempo & $\%$ & Tempo \\
\hline RMR & 32,1 & 7,4 & 45,1 & 9,8 & 22,8 & 7,0 \\
\hline RMSA & 50,0 & 6,8 & 37,9 & 10,0 & 12,1 & 6,7 \\
\hline $\mathrm{RMBH}$ & 35,9 & 4,6 & 39,3 & 7,7 & 24,7 & 5,3 \\
\hline RMRJ & 34,6 & 8,3 & 51,5 & 10,8 & 13,9 & 8,5 \\
\hline RMSP & 36,4 & 7,5 & 48,4 & 9,8 & 15,2 & 7,6 \\
\hline RMPA & 36,4 & 6,7 & 49,7 & 10,8 & 13,9 & 7,9 \\
\hline BRASIL & 37,9 & 6,7 & 44,7 & 9,7 & 17,5 & 6,8 \\
\hline
\end{tabular}

Fonte: Elaboração própria com base nos dados da Pesquisa Mensal de Emprego (2000).

Em relação ao tempo médio de duração do desemprego, constata-se que os trabalhadores que conseguiram inserção no mercado de trabalho, ao longo dos quatro meses, apresentam uma duração média do desemprego (6,7 meses) inferior quando comparada aos que permaneceram desempregados (9,7 meses) ou tornaram-se inativos (6,8 meses). Devem-se analisar tais resultados com cautela, haja vista que se trata de uma informação censurada para os trabalhadores desempregados e que continuam na busca pelo emprego. No entanto, esse resultado pode servir como mais um indício de que o tempo de duração no estado de desemprego tende a acarretar prejuízos para a condição de atividade futura do trabalhador.
Outra investigação pode ser feita pela análise comparativa entre o salário/hora médio dos trabalhadores que permanecerem ocupados e o daqueles que estavam desocupados e que conseguiram inserção no mercado de trabalho (no tempo $t=4$ ). $\mathrm{O}$ intuito é verificar um possível prejuízo financeiro acarretado pelo período de tempo que o trabalhador esteve desempregado. Para tal, a amostra foi, por um lado, ampliada aos trabalhadores ocupados (73.955) e, por outro lado, restrita aos que estavam desempregados no tempo $t=1$ e que conseguiram uma ocupação remunerada no tempo $\mathrm{t}=4$ (2.006), de forma que a amostra total foi de 75.961 trabalhadores. Os resultados encontram-se na Tabela 2, na qual se verifica que, apenas nos meses de maio e julho, 
os trabalhadores recém-ocupados obtiveram um salário/hora médio superior ao daqueles que já estavam ocupados. Nos demais meses, os trabalhadores já ocupados recebiam um salário/hora médio superior. No período como um todo (última linha da tabela), verifica-se que a diferença de salários entre os trabalhadores, conforme sua situação, é estatisticamente significativa (teste $t=2,397)$ e favorável aos trabalhadores que já estavam ocupados.

Em seguida, a amostra foi restrita aos desempregados, que, durante o período de acompanhamento da pesquisa, conseguiram uma ocupação formal. Entende-se, nesse contexto, uma ocupação formal os traba-

\section{Tabela 2 _ Brasil metropolitano. Teste da igualdade de médias para o salário/hora,} por tempo de duração do desemprego - 2000

\begin{tabular}{|c|c|c|c|c|}
\hline \multirow{2}{*}{ Mês } & \multirow{2}{*}{ Situação } & \multicolumn{2}{|c|}{ Salário/hora } & \multirow{2}{*}{$\begin{array}{l}\text { Teste de Igualdade de } \\
\text { Médias (Teste - T) }\end{array}$} \\
\hline & & Média & Desvio Padrão & \\
\hline \multirow{2}{*}{ Abril } & Permaneceu Ocupado & 7,3792 & 16,5550 & \multirow{2}{*}{0,851} \\
\hline & Desocupado $\rightarrow$ Ocupado & 6,4115 & 16,5098 & \\
\hline \multirow{2}{*}{ Maio } & Permaneceu Ocupado & 8,3417 & 22,6193 & \multirow{2}{*}{$-0,124$} \\
\hline & Desocupado $\rightarrow$ Ocupado & 8,5935 & 28,2688 & \\
\hline \multirow{2}{*}{ Junho } & Permaneceu Ocupado & 7,5044 & 17,1147 & \multirow{2}{*}{0,507} \\
\hline & Desocupado $\rightarrow$ Ocupado & 6,8773 & 19,1675 & \\
\hline \multirow{2}{*}{ Julho } & Permaneceu Ocupado & 7,6835 & 16,3821 & \multirow{2}{*}{$-0,545$} \\
\hline & Desocupado $\rightarrow$ Ocupado & 8,3037 & 42,1816 & \\
\hline \multirow{2}{*}{ Agosto } & Permaneceu Ocupado & 7,0959 & 14,7650 & \multirow{2}{*}{2,093} \\
\hline & Desocupado $\rightarrow$ Ocupado & 5,1188 & 14,0493 & \\
\hline \multirow{2}{*}{ Setembro } & Permaneceu Ocupado & 8,4321 & 21,4246 & \multirow{2}{*}{3,051} \\
\hline & Desocupado $\rightarrow$ Ocupado & 4,3675 & 11,7354 & \\
\hline \multirow{2}{*}{ Outubro } & Permaneceu Ocupado & 7,7051 & 19,5411 & \multirow{2}{*}{0,532} \\
\hline & Desocupado $\rightarrow$ Ocupado & 7,0341 & 21,6952 & \\
\hline \multirow{2}{*}{ Novembro } & Permaneceu Ocupado & 8,5600 & 20,7753 & \multirow{2}{*}{0,123} \\
\hline & Desocupado $\rightarrow$ Ocupado & 8,3967 & 21,7403 & \\
\hline \multirow{2}{*}{ Dezembro } & Permaneceu Ocupado & 8,3612 & 19,0769 & \multirow{2}{*}{0,464} \\
\hline & Desocupado $\rightarrow$ Ocupado & 7,7746 & 23,4489 & \\
\hline \multirow{2}{*}{ MÉDIA } & Permaneceu Ocupado & 7,8972 & 18,8653 & \multirow{2}{*}{2,397} \\
\hline & Desocupado $\rightarrow$ Ocupado & 6,8663 & 23,6070 & \\
\hline
\end{tabular}

Fonte: Elaboração própria com base nos dados da Pesquisa Mensal de Emprego (2000). 
lhadores contratados com carteira assinada, militares ou estatutários. Desta forma, são excluídos os empregadores, "conta própria" e os trabalhadores sem carteira assinada. Assim, a base de dados do estudo reduziu para 2.990 trabalhadores ocupados (62,3\% homens e 37,7\% mulheres) no Brasil metropolitano. Portanto, foram excluídos da análise os que permaneceram desempregados ou tornaram-se inativos e os que nunca estiveram ocupados. Logo, o número de indivíduos por região também sofreu alteração, apresentando os seguintes resultados: RMR (344), RMSA (690), RMBH (627), RMRJ (326), RMSP (577) e RMPA (426).

A informação do tempo médio de desemprego serve como primeiro diagnóstico para uma análise mais detalhada acerca da busca pelo emprego, pois, como se sabe, a duração do desemprego não é uniforme, ela varia conforme os diferentes segmentos da população economicamente ativa. É importante destacar que a informação sobre o tempo de duração do desemprego reporta-se à duração completa do estado de desemprego para o estado de ocupado, dado que se tem conhecimento do período total que o trabalhador ficou desempregado até conseguir sua inserção ocupacional.

Nesse sentido, é de se esperar que os indivíduos menos exigentes em relação a uma futura ocupação (ou que necessitem, de forma extremamente urgente, de um emprego) permaneçam um tempo menor na situação de desempregado. A Tabela 3, contém as informações relativas aos indivíduos, de acordo com seus atributos, que transitaram da condição de desocupado para a de ocupado, mais especificamente sobre o tempo completo de duração e a probabilidade de permanência no desemprego antes dos seis, nove e doze primeiros meses. Nessa, percebe-se que os homens, os jovens com idade até 20 anos e os trabalhadores e os chefes de família são os que demoram, na média, um tempo inferior para conseguir a inserção ocupacional. Ademais, nota-se que existe um diferencial significativo do tempo de desemprego entre as regiões metropolitanas, variando de 4,58 meses na RMBH a 7,48 meses na RMRJ.

Esse resultado destaca que não existe relação direta, a priori, entre taxa de desemprego e duração do desemprego, visto que a Região Metropolitana do Rio de Janeiro (RMRJ), nas últimas décadas, caracterizou-se por deter os menores índices de desemprego no País. Na questão da duração completa do desemprego, essa região (RMRJ), aparentemente antagônica no que respeita à dinâmica do mercado de trabalho, apresentou o maior período completo de desemprego. 
Tabela 3_ Brasil metropolitano. Duração do desemprego, em meses, desvio padrão e probabilidade de permanência igual ou inferior a 6 meses - 2000

\begin{tabular}{|c|c|c|c|c|c|}
\hline \multicolumn{2}{|c|}{ Variável } & \multirow{2}{*}{$\begin{array}{c}\text { Tempo } \\
6,201 \\
\end{array}$} & \multirow{2}{*}{$\begin{array}{c}\mathbf{P} \leq \mathbf{6} \\
\mathbf{( \% )}\end{array}$} & \multirow{2}{*}{$\begin{array}{c}\begin{array}{c}\mathbf{P} \leq \mathbf{9} \\
\mathbf{( \% )}\end{array} \\
80,69 \\
\end{array}$} & \multirow{2}{*}{$\begin{array}{c}\mathbf{P} \leq \mathbf{1 2} \\
\mathbf{( \% )}\end{array}$} \\
\hline \multirow{2}{*}{ Gênero } & Homem & & & & \\
\hline & Mulher & 6,506 & 64,11 & 79,55 & 85,63 \\
\hline \multirow{5}{*}{ Faixa Etária } & De 16 a 20 anos & 5,765 & 68,51 & 83,39 & 89,27 \\
\hline & De 21 a 24 anos & 6,408 & 65,95 & 79,01 & 84,46 \\
\hline & De 25 a 30 anos & 6,400 & 64,49 & 78,73 & 85,43 \\
\hline & De 31 a 40 anos & 6,677 & 66,77 & 78,55 & 83,23 \\
\hline & Mais de 40 anos & 6,266 & 67,60 & 82,12 & 86,78 \\
\hline \multirow{4}{*}{$\begin{array}{l}\text { Condição na } \\
\text { Família }\end{array}$} & Chefe & 4,667 & 80,95 & 90,48 & 91,67 \\
\hline & Cônjuge & 6,215 & 67,66 & 80,53 & 84,82 \\
\hline & Filho & 5,995 & 68,47 & 81,45 & 86,94 \\
\hline & Outros & 5,981 & 67,31 & 84,62 & 88,46 \\
\hline \multirow{6}{*}{ Escolaridade } & Analfabeto & 6,721 & 63,83 & 78,66 & 84,62 \\
\hline & $1^{\circ}$ grau inc. & 7,000 & 62,98 & 75,96 & 82,69 \\
\hline & $1^{\circ}$ grau comp. & 5,964 & 69,22 & 81,76 & 86,70 \\
\hline & $2^{\circ}$ grau inc. & 6,582 & 61,85 & 79,69 & 85,54 \\
\hline & $2^{\circ}$ grau comp. & 6,482 & 65,52 & 79,23 & 85,66 \\
\hline & Superior & 6,873 & 66,34 & 79,02 & 80,98 \\
\hline \multirow{6}{*}{$\begin{array}{l}\text { Região } \\
\text { Metropolitana }\end{array}$} & RMR & 7,384 & 55,52 & 74,42 & 76,74 \\
\hline & RMSA & 6,467 & 65,70 & 72,97 & 83,14 \\
\hline & $\mathrm{RMBH}$ & 4,579 & 79,59 & 90,91 & 93,78 \\
\hline & RMRJ & 7,480 & 59,44 & 75,85 & 82,66 \\
\hline & RMSP & 6,459 & 66,55 & 83,19 & 87,92 \\
\hline & RMPA & 6,692 & 63,62 & 80,52 & 84,74 \\
\hline & SIL & $6,315$. & $66,633$. & 66,63 & 80,26. \\
\hline
\end{tabular}

Fonte: Elaboração própria com base nos dados da Pesquisa Mensal de Emprego (2000). 
Ainda na Tabela 3, a última coluna descreve os valores da probabilidade de permanência por no máximo $6 / 9$ ou 12 meses no desemprego. Essa indica que as menores chances de conseguir uma inserção (nesse intervalo) pertencem aos trabalhadores com nível superior de escolaridade $(80,9 \%)$, os com idade entre 31 e 40 anos $(83,2 \%)$ e os cônjuges $(84,8 \%)$. Possivelmente, dois fatores distintos sejam as causas desse cenário:

1. No que diz respeito aos trabalhadores com escolaridade superior e aos com idade entre 31 e 40 anos, acredita-se que o nível de exigência em relação ao tipo de ocupação e ao salário que vai receber seja maior, elevando dessa forma o seu salário de reserva e dificultando sua imediata contratação. Esse resultado está de acordo com as discussões feitas anteriormente e pode ser explicado à luz das teorias da procura por emprego, que ajudam a elucidar o comportamento dos indivíduos nesse tipo de situação. Segundo tais teorias, um nível de educação superior está associado a rendimentos esperados maiores, o que pode significar maior salário de reserva em termos relativos para os indi- víduos mais educados, implicando, assim, um tempo de procura por emprego maior. De acordo com Malbouisson e Menezes (2004), a probabilidade de saída do desemprego para a condição de empregado é uma função decrescente da quantidade de educação dos indivíduos. Os autores observaram que aqueles desempregados com nível de escolaridade médio completo ou mais apresentam duração média superior à daqueles das demais categorias.

2. E, com respeito ao cônjuge, o fato de o chefe de família ser tradicionalmente o responsável pelo sustento do lar pode reduzir a intensidade da busca pelo trabalho, aumentando o seu período de desemprego.

Embora se saiba que existem os chamados "benefícios do desemprego", 11 é fato comum na literatura especializada (Burtless, 1987; Layard et al., 1991; Katz e Meyer, 1990; Corak e Jones, 1995) que o período de tempo que o trabalhador permanecer desempregado pode trazer prejuízos para a sua reinserção no mercado de trabalho, tanto no curto prazo, devido à falta da renda proveniente do seu esforço (salário) do qual se utiliza para adquirir sua

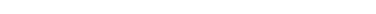

11 Entre os benefícios do desemprego, estão, principalmente, aqueles associados às Políticas Passivas de Emprego, na qual se insere o seguro-desemprego como principal expoente dos chamados Programas de Reposição de Renda. 
cesta de consumo, como no médio e longo prazo, por meio do recebimento de um salário inferior ao esperado. Bover, Arellano e Bentolila (2002), em estudo sobre o mercado de trabalho da Espanha, também observaram que a probabilidade de encontrar um emprego diminui com a duração do desemprego, principalmente para os indivíduos que estejam há mais de um ano desempregado. Isso pode ocorrer em função dos custos gerados pelo desemprego, como a possível perda de capital humano - vista pelo empregador como um atributo importante na hora de contratar uma mão de obra - e diminuição do seu salário de reserva em razão do desgaste financeiro e psicológico gerado pela procura do emprego (Pissarides, 1992; Blanchard e Diamond, 1994).

Assim, no contexto deste artigo, uma variável importante a ser utilizada na determinação salarial é o tempo de permanência no desemprego - duração do desemprego. Para demonstrar a influência do período que o trabalhador passou desempregado no seu salário (salário/hora), foram estimadas regressões por Mínimos Quadrados Ordinários e Quantílicas, no capítulo seguinte.

\section{Análise econométrica: resultados empíricos}

Os resultados das estimações das equações 7, 8 e 9 estão descritos na Tabela 4.
Com base nos parâmetros estimados na equação 7 , podem-se fazer as seguintes constatações: homens têm maior remuneração em relação às mulheres; quanto mais idade tiver o trabalhador, maior tende a ser o seu salário (possivelmente refletindo o acúmulo de capital humano e da experiência); níveis elevados de escolaridade estão relacionados a maiores salários; os chefes de família têm maior rendimento em relação às demais classes da condição familiar, e os trabalhadores da Região Metropolitana de São Paulo (RMSP), com as mesmas características dos indivíduos das demais regiões, recebem maiores salários comparativamente ao de todas as outras.

Segundo os resultados encontrados, os trabalhadores que saíram da situação de desemprego recebem, em média, 30\% a menos do que os demais trabalhadores, um claro indício da penalidade causada pela permanência no desemprego por algum período de tempo. A simples comparação entre as médias sugeriu que a média dos que não estiveram em situação de desemprego é duas vezes superior à média salarial dos recém-empregados. Boa parte dessa diferença entre médias é explicada, portanto, pelas diferentes características dos indivíduos da amostra. 
Tabela 4_Brasil metropolitano. Coeficientes estimados das equações 7, 8 e 9 - 2000

\begin{tabular}{|c|c|c|c|c|}
\hline \multirow{2}{*}{\multicolumn{2}{|c|}{ Variável }} & \multicolumn{3}{|c|}{ quação } \\
\hline & & Equação 7 & Equação 8 & Equação 9 \\
\hline Gênero & Homem & $0,304^{*}$ & $0,304 *$ & $0,304 *$ \\
\hline \multirow{4}{*}{ Faixa Etária } & Até 20 anos & $-0,795^{*}$ & $-0,797 *$ & $-0,797 *$ \\
\hline & De 21 a 24 anos & $-0,594 *$ & $-0,595^{*}$ & $-0,595^{*}$ \\
\hline & De 25 a 30 anos & $-0,374 *$ & $-0,375^{*}$ & $-0,374 *$ \\
\hline & De 31 a 40 anos & $-0,193^{*}$ & $-0,193 *$ & $-0,193^{*}$ \\
\hline \multirow{3}{*}{ Condição na Família } & Chefe & $0,088^{*}$ & $0,087 *$ & $0,087^{*}$ \\
\hline & Cônjuge & $0,078^{*}$ & $0,078 *$ & $0,077^{*}$ \\
\hline & Filho & $-0,017$ & $-0,017$ & $-0,017$ \\
\hline \multirow{5}{*}{ Região Metropolitana } & RMRE & $-0,478^{*}$ & $-0,477^{*}$ & $-0,477 *$ \\
\hline & RMSA & $-0,408^{*}$ & $-0,408^{*}$ & $-0,408^{*}$ \\
\hline & $\mathrm{RMBH}$ & $-0,320 *$ & $-0,320 *$ & $-0,320 *$ \\
\hline & RMRJ & $-0,095^{*}$ & $-0,094 *$ & $-0,094 *$ \\
\hline & RMPA & $-0,210^{*}$ & $-0,210^{*}$ & $-0,210^{*}$ \\
\hline \multirow{2}{*}{ Setor de Atividade } & Primário & $0,121 *$ & $0,121 *$ & 0,121 \\
\hline & Secundário & $0,087^{*}$ & $0,087 *$ & 0,087 \\
\hline \multirow{5}{*}{ Escolaridade } & $1^{\circ}$ grau inc. & $0,345^{*}$ & $0,346^{*}$ & $0,347^{*}$ \\
\hline & $1^{\circ}$ grau comp. & $0,505^{*}$ & $0,505^{*}$ & $0,505^{*}$ \\
\hline & $2^{\circ}$ grau inc. & $1,160^{*}$ & $1,160 *$ & $1,163 *$ \\
\hline & $2^{\circ}$ grau comp. & $0,989^{*}$ & $0,989 *$ & $0,990^{*}$ \\
\hline & Superior & $1,955^{*}$ & $1,955^{*}$ & $1,958^{*}$ \\
\hline Situação & Desempregado & $-0,272 *$ & - & - \\
\hline Tempo de desemprego & Meses & - & $-0,032 *$ & - \\
\hline \multirow{5}{*}{$\begin{array}{l}\text { Escolaridade } \mathrm{x} \text { tempo } \\
\text { de desemprego }\end{array}$} & Superior $\mathrm{x}$ tempo & - & - & $-0,090 *$ \\
\hline & $1^{\circ}$ grau inc. $\mathrm{x}$ tempo & - & - & $-0,022$ \\
\hline & $1^{\circ}$ grau comp. $x$ tempo & - & - & $-0,021 *$ \\
\hline & $2^{\circ}$ grau inc. $x$ tempo & - & - & $-0,061 *$ \\
\hline & $2^{\circ}$ grau comp. $x$ tempo & $\therefore$ & - & $-0,031 *$ \\
\hline
\end{tabular}

*Indica significância no nível de 1\%; ** Indica significância no nível de 5\%; *** Indica significância no nível de $10 \%$.

Fonte: Elaboração própria com base nos dados da Pesquisa Mensal de Emprego (2000).

Nos resultados da estimação da equação 8, em que se investigam os efeitos da duração do desemprego sobre o salário, obtém-se as mesmas constatações do diferencial salarial por gênero, idade, educação, condição na família e setor de atividade 
econômica. Conforme o resultado da estimação do parâmetro da variável duração do desemprego, para cada mês adicional sem emprego, o indivíduo tem uma queda em seu salário da ordem de 3\%. Portanto, além dos recém-empregados possuírem salários mais baixos do que os trabalhadores que não estavam desempregados, quanto mais tempo eles levam para encontrar um novo emprego, menores serão seus salários.

Os efeitos da duração do desemprego sobre o salário mudam conforme seja o nível de escolaridade do trabalhador, segundo as estimações da equação 9. Para os de nível superior, um mês adicional na situação de desemprego resulta numa redução de salário, em média, de 9,4\%. Para os indivíduos com segundo grau completo ou incompleto, cada mês desempregado ocasiona um decréscimo de 6,2\% e 3,2\%. Entre os trabalhadores com primeiro grau completo e incompleto, essa redução é de 2,2\% em ambos os grupos; porém, esse parâmetro não é estatisticamente significante quando os indivíduos possuem o primeiro grau incompleto. Portanto, os resultados encontrados sugerem que, quanto maior o tempo de desemprego, menor será o salário no reemprego, e o efeito da duração do desemprego sobre os salários é maior entre os mais escolarizados.
Com relação aos resultados das regressões quantílicas da equação 10 (ver Tabela 5), nota-se que, em quase todos os quantis, prevaleceram os resultados constatados no modelo OLS. No entanto, ressalta-se o fato de o valor estimado do parâmetro da variável escolaridade superior, além de significativo, ser o de maior valor absoluto, quando comparado aos demais níveis de escolaridade, principalmente nos quantis mais elevados da distribuição condicional do salário/hora. Para os demais níveis de escolaridade, os valores dos parâmetros estimados também foram maiores nos quantis mais elevados da distribuição condicional do salário, mostrando que a diferença educacional entre os indivíduos da amostra afeta mais os rendimentos daqueles que recebem os maiores salários.

Comparativamente à RMSP, em todas as demais regiões - e para todos os quantis -, os trabalhadores recebem salário inferior. As maiores disparidades salariais foram encontradas nas Regiões Metropolitanas de Recife e Salvador. Contudo, tal diferencial de salários entre as regiões metropolitanas, com relação a São Paulo, diminui na medida em que se caminha paras os quantis superiores da distribuição de salários. Ou seja, a diferença inter-regional de salários é superior nos quantis inferiores da distribuição condicional de salários. 
Tabela 5_ Brasil metropolitano. Coeficientes estimados da regressão quantílica (equação 10) - 2000

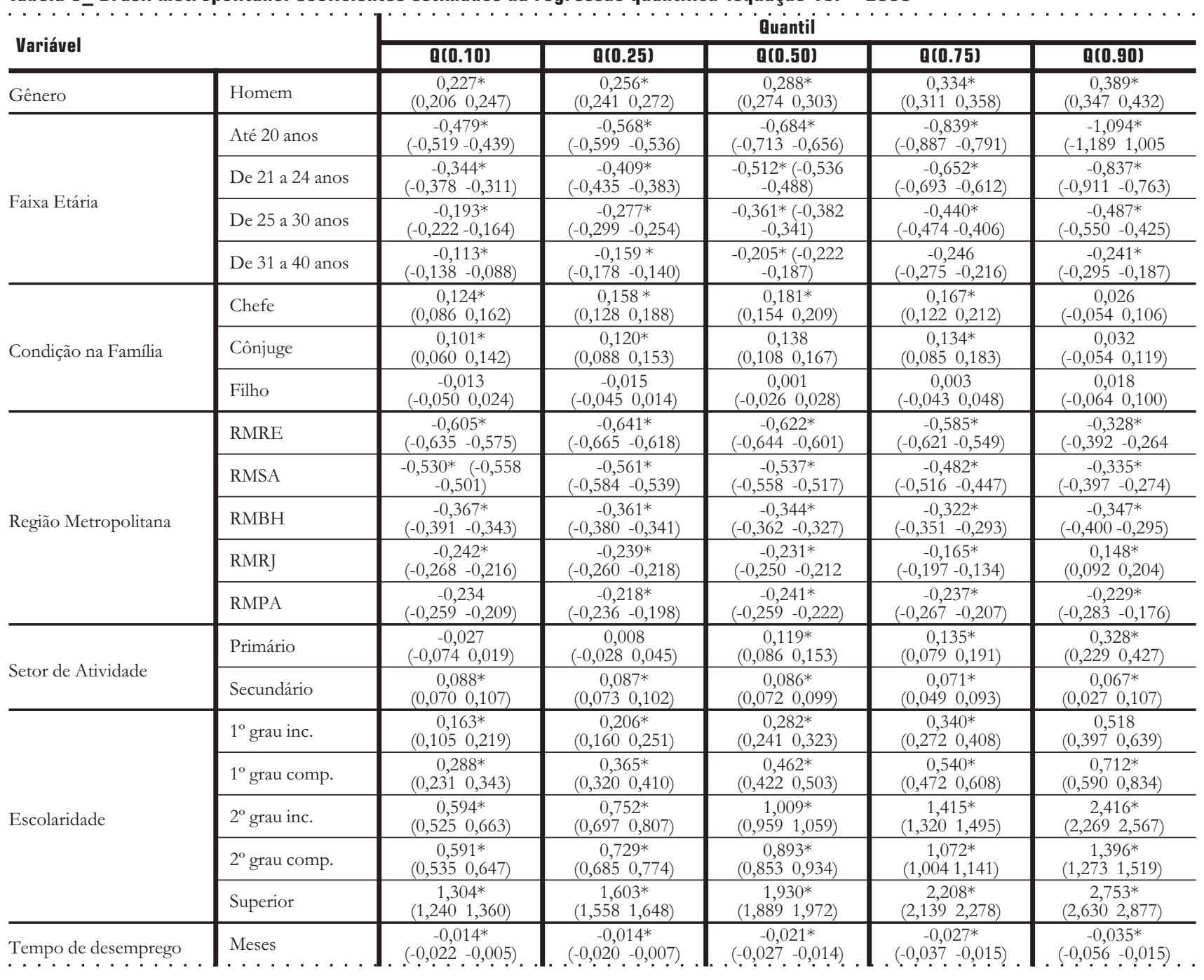

Os valores apresentados são o coeficiente estimado e, entre parênteses, o intervalo de confiança. * Indica significância no nível de $10 \%$

Fonte: Elaboração própria com base nos dados da Pesquisa Mensal de Emprego (2000). 
O coeficiente estimado para a variável duração do desemprego, em todos os quantis, foi estatisticamente significante. Seu sinal negativo indica que a permanência no desemprego gera redução do salário recebido. Nota-se, entretanto, que o tempo de desemprego afeta mais aqueles situados nos quantis mais elevados da distribuição condicional de salários. No quantil 0.1, por exemplo, um mês adicional de desemprego acarreta num diferencial de salários de 1,4\%. No quantil 0.9, essa diferença é de 3,6\%.

A equação 10 foi estimada nos quantis intermediários aos quantis $\{0.10,0.25$, $0.50,0.75,0.90\}$, e os resultados para o parâmetro de tempo de permanência no de- semprego estão exibidos no Gráfico 1. Nota-se, claramente, que a penalização em razão da maior permanência no desemprego é mais elevada nos quantis superiores da distribuição condicional do salário, corroborando os resultados já encontrados na estimação da equação 10 (apresentados na Tabela 5).

Valendo-se das premissas básicas da teoria da oferta de trabalho que confere ao trabalhador a escolha de permanecer desempregado - baseado em seu salário de reserva e nos fatores que o influenciam -, os resultados mostram que, se o trabalhador elevar consideravelmente o seu salário de reserva ou igualá-lo aos salários efetivamente

Gráfico 1_ Brasil metropolitano. Parâmetro estimado da variável permanência no desemprego nos quantis intermediários aos quantis $\{0.10,0.25,0.50,0.75,0.90\}-2000$

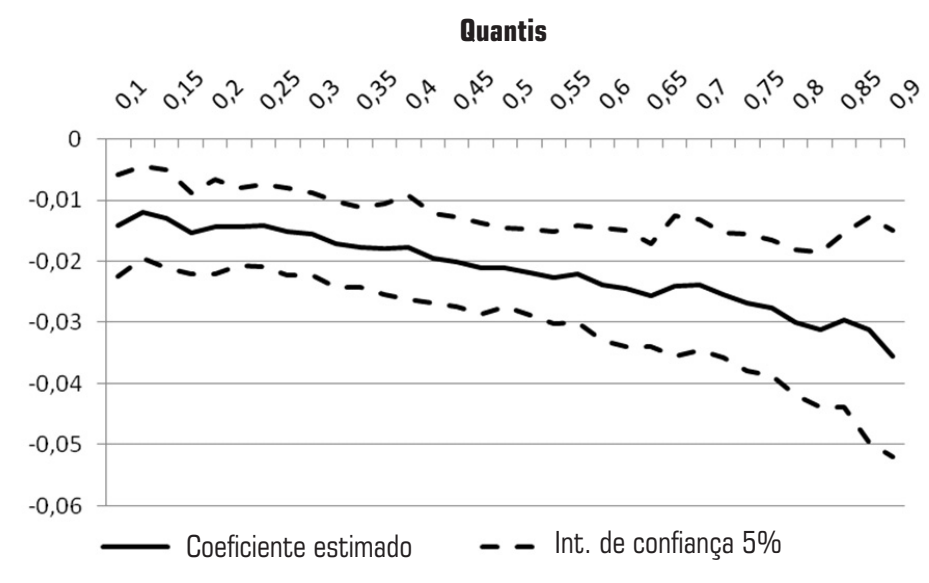

Fonte: Elaboração própria com base nos dados da Pesquisa Mensal de Emprego (2000). 
pagos, poderá haver consequências negativas em seus salários ou ele terá bastante dificuldade de conseguir um novo emprego.

Os resultados da equação 11 estão registrados na Tabela 6. Quando estimado na média da distribuição condicional de salários, o parâmetro indicativo da perda salarial por conta do tempo de desemprego foi estatisticamente significativo para todos os níveis educacionais considerados, excetuando-se o primeiro grau incompleto. Todavia, ao analisar as estimações por quantil, constata-se que apenas aqueles de nível superior e com segundo grau completo são penalizados, não importando o quantil onde estejam na distribuição condicional dos salários. Nota-se ainda que, para aqueles com nível superior, a perda para quem está no quantil 0.90 é mais do que o dobro da perda salarial sofrida pelos indivíduos desse nível de escolaridade situados no quantil 0.10 . Tais resultados sugerem maior perda para os empregados nos postos de trabatho que exigem maior qualificação.

Por último, temos o Gráfico 2, que mostra as estimativas da equação 11 , em quantis intermediários aos quantis $\{0.10$, $0.25,0.50,0.75,0.90\}$, apenas para o parâmetro indicativo da penalidade da permanência no desemprego dos indivíduos com nível de escolaridade superior. Os resultados apresentados corroboram os já repor- tados na Tabela 6, mostrando que os indivíduos mais escolarizados são os mais pe- nalizados pela permanência no desemprego e, entre esses, os trabalhadores recém-empregados nos melhores postos de trabalho são os que têm maior perda salarial.

\section{6_Considerações finais}

Este trabalho procurou discutir um aspecto pouco aprofundado nas discussões empíricas no Brasil, ao fornecer novas evidências sobre os custos gerados pelo tempo de permanência no desemprego, mais especificamente, sobre os efeitos que o período da procura pelo emprego acarreta no salário do trabalhador.

Os resultados obtidos corroboram as evidências usualmente apontadas pela literatura especializada sobre as consequências salariais da duração do desemprego, indicando que esse fenômeno atinge de forma diferenciada os diversos segmentos da população. Logo, os efeitos causados pelo maior tempo despendido na busca de uma ocupação também são distintos.

Pelas análises descritivas e estimações feitas (mínimos quadrados ordinários e regressões quantílicas), foi possível identificar importantes observações, das quais desejamos ressaltar três: 
Tabela 6_ Brasil metropolitano. Coeficientes estimados da regressão quantílica (equação 11) - 2000

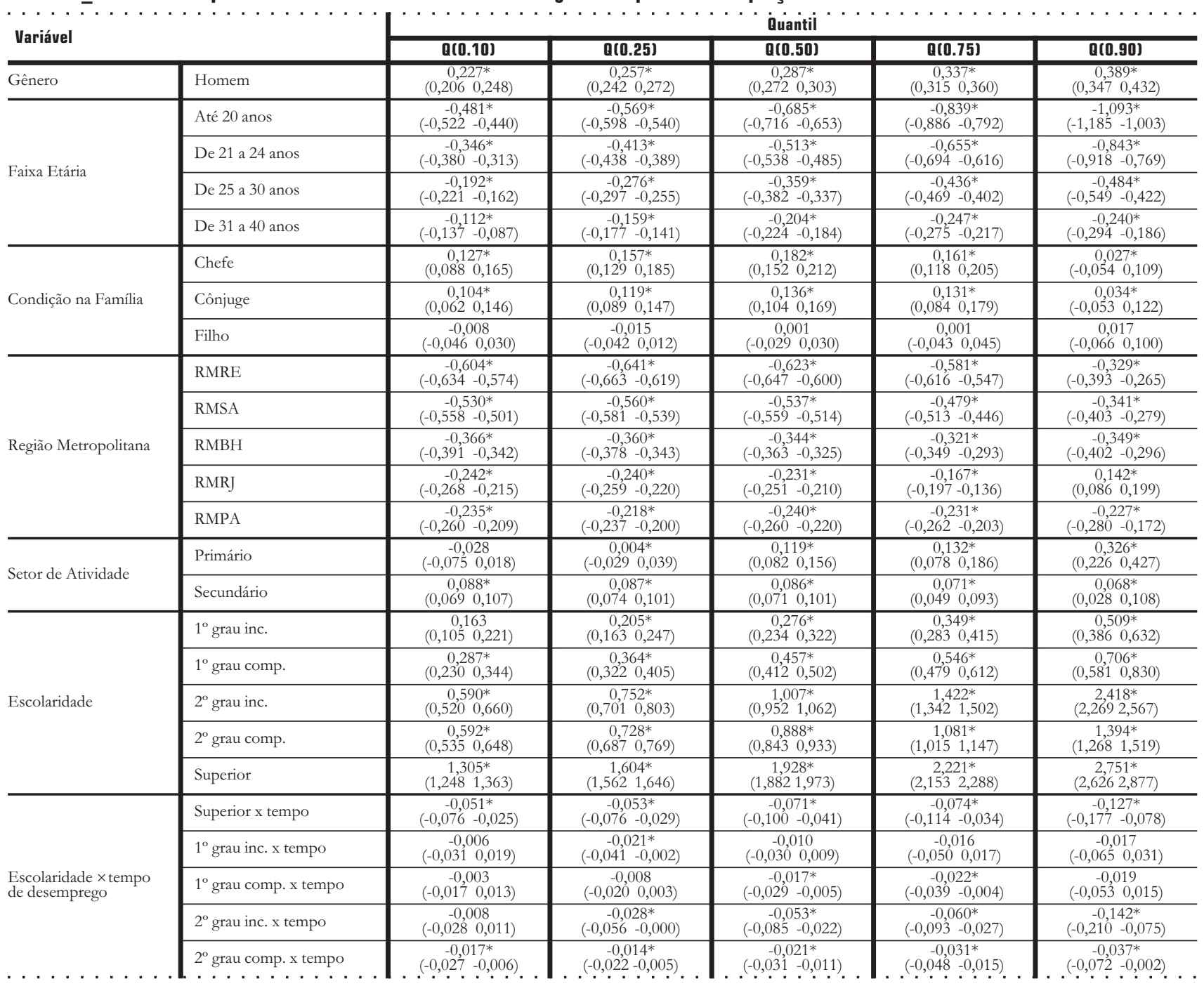

Os valores apresentados são o coeficiente estimado e, entre parênteses, o intervalo de confiança. * Indica significância no nível de $10 \%$.

Fonte: Elaboração própria com base nos dados da Pesquisa Mensal de Emprego (2000). 
Gráfico 2_Brasil metropolitano. Parâmetro estimado da variável permanência no desemprego nos quantis intermediários aos quantis $\{0.10,0.25,0.50,0.75,0.90\}$, para os indivíduos com nível de escolaridade superior - 2000

\section{Quantis}

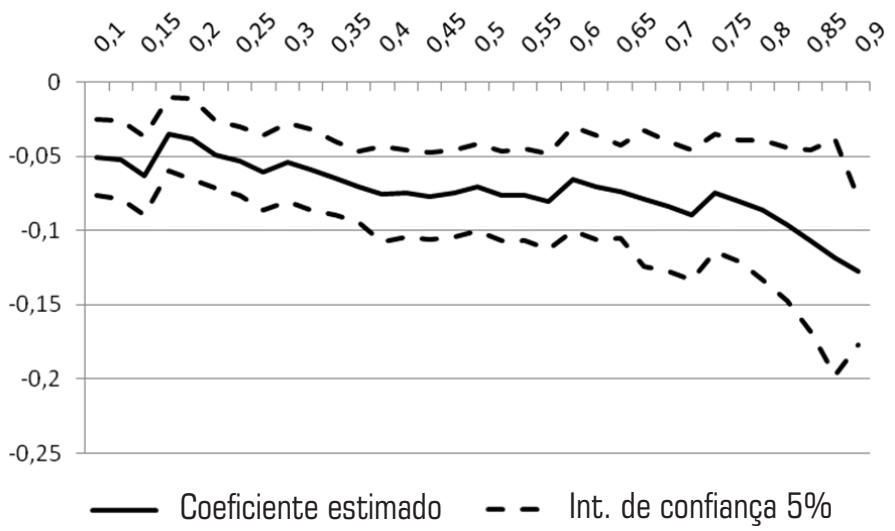

Fonte: Elaboração própria com base nos dados da Pesquisa Mensal de Emprego (2000).

- A primeira reporta-se à característica comum observada entre os homens, os trabalhadores com nível de escolaridade superior e aqueles com faixa etária mais elevada, que apresentaram os maiores períodos de duração completa do desemprego. Esse maior período que passam na busca de uma ocupação é reflexo do maior salário de reserva que possuem, tanto que tais grupos apresentaram a melhor remuneração (em termos de salário-hora).
- A segunda constatação refere-se ao sinal e à intensidade do coeficiente estimado através das regressões da variável duração do desemprego. O sinal negativo estimado indica que, caso o trabalhador conseguisse reduzir o tempo da busca pelo emprego, ele teria um acréscimo significativo no seu salário. Neste estudo, observou-se que, cada mês que o trabalhador permanece no estado de desemprego, isso acarreta uma redução de, aproximadamente, $3,0 \%$ 
no salário. Logo, considerando que existem categorias de trabalhadores que, por diversos motivos sociais e econômicos, permanecem mais tempo na procura do emprego, maior será o efeito redutor no salário causado para esses grupos. Como exemplo, um trabalhador com nível superior de escolaridade tem uma redução média de 10,0\% no salário.

- A terceira evidência diz respeito ao grupo de trabalhadores com nível de escolaridade superior. Estes, embora tenham o maior rendimento (salário/hora), são os mais prejudicados em termos de perda salarial, provocada pelo período que estiveram à procura de um emprego. Ademais, os coeficientes estimados, tanto na equação estimada por mínimos quadrados ordinários quanto nas regressões quantílicas, apresentaram valores negativos, de forte intensidade e próximos, indicando que a redução salarial ocorre de forma homogênea ao longo do período.

Isso posto, percebeu-se que, se por um lado a busca seletiva pelo emprego, demonstrada no maior tempo médio de de- semprego de determinados grupos, pode contribuir para melhor inserção ocupacional, por outro lado ela pode ser fator negativo na determinação do salário. Sabe-se que uma parcela significativa dos trabalhadores desempregados possui uma renda do não trabalho (seja através de um auxílio financeiro do governo - com programas como seguro-desemprego -, seja por meio de uma pensão ou ajuda familiar). Isso, ao mesmo tempo em que retarda o ingresso ocupacional do trabalhador, possibilitando-lhe melhor escolha ótima, por outro lado acaba expandindo o seu tempo de desemprego (fora da ocupação), que, como visto neste trabalho, gera uma redução das oportunidades de reinserção ocupacional (Blanchard e Diamond, 1994; Crémieux et al., 1995) e também no salário auferido no novo emprego.

Não se pretende com isso negar a importância das Políticas de Emprego, visto que elas são fundamentais para oferecer melhores condições aos trabalhadores, estejam eles ocupados ou em busca do emprego (desempregados). No entanto, é importante destacar que qualquer que seja a estratégia, em termos de política adotada pelo governo no mercado de trabalho, deve-se sempre ser levada em consideração a necessidade imperiosa de reduzir o tempo de desemprego mediante a ampliação das 
chances de inserção ocupacional. Qualquer outra solução implementada tenderá a ter caráter paliativo, que, no longo prazo, poderá gerar prejuízos ao trabalhador.

Por fim, acredita-se que apenas com crescimento econômico sustentado, por um período relativamente longo, e políticas de intermediação de mão de obra mais eficientes e que sejam capazes de agilizar o processo de obtenção do emprego, será possível suprir a falta de vagas no mercado de trabalho e reduzir os custos gerados pelo período de desemprego. 


\section{Referências bibliográficas}

\author{
ADDISON, J. T.; PORTUGAL, P. \\ Job displacement, relative wage \\ changes, and duration of \\ unemployment. Journal of Labour \\ Economics, v. 7, p. 281-302, 1989.
}

ADDISON, J. T.; BLACKBURN, M.L.; COTTI, C. D. New estimates of the effects of minimum wages in the U.S. retail sector. 2008. (IZA Discussion Paper, 3597).

BLANCHARD, O. J.; DIAMOND, P. Ranking, unemployment duration and wages. Review of Economic Studies, v. 61 , n. 208 , p. $417-434,1994$

BORJAS, G. J. Labor Economics. New York. Mc Graw-Hill, 1996.

BOVER, O.; ARELLANO, M.; BENTOLIA, S. Unemployment duration, benefit duration and the business cicle. The Economic Journal, n. 112, p. 223-265, Apr. 2002.

BURTLESS, G. Jobless pay and high European unemployment. In: LAWRENCE, R.; SCHULTZ, C. Barrier in European Growth. Washington: The Book Institution. 1987.

CLARK, K. B.; SUMMER, L. H. Unemployment insurance and labour market transitions. In: SUMMERS, L. H. Underestanding Unemployment. Massachusetts: The MIT Press, Cambridge, 1992.
CRÉMIEUX, P. Y.; FORTIN, P.; STORER, P.; VAN

AUDENRODE, M. L'incidence de

l'assurance-chomage sur les salaires,

l'intensite de la recherche d'emploi et la probabilite de reemploi. Gouvernement du Canada - Human Resources, n. $27,1995$.

CORAK, M.; JONES, S. R. G. The persistence unemployment insurance benefits? How important were regional extended

unemployment insurance benefits? Canadian Journal of Economics, v. 28, p. 555-67, 1995.

DECKER, C. K. G.; LEVINE, P. B. Less-skilled workers, welfare reform and the unemployment insurance system. Research in Labor Economics, v. 20, p. 395-432, 2001.

DEN HAAN, W. J.; HAEFKE, C.; RAMEY, G. Shocs and institutions in a job matcbing model. Working Paper, 2001.

ERIKSSON, T.; LILJA, R.; TORP, H. Determinants of job search intensity some evidence from the Nordic Coutries. Institute for Social Research. Oslo. 2002.

Disponível em: <http:// www.labour.fi/tutkimusjulk/ tyopaperit/sel185.pdf>. Acesso em: 10 abr. 2007.
GREGORY, M.; JUKES, R. Unemployment and subsequent earnings: Estimating scarring among British men 1984-94. Economic Journal, v. 111, n. 475, p. 607 e 625, 2001.

INSTITUTO BRASILEIRO DE GEOGRAFIA E ESTATÍSTICA IBGE. Pesquisa Mensal de Emprego. Rio de Janeiro, 2000.

INSTITUTO BRASILEIRO DE GEOGRAFIA E ESTATÍSTICA IBGE. Pesquisa Mensal de Emprego: Notas Metodológicas. Rio de Janeiro, 1999.

INSTITUTO BRASILEIRO DE GEOGRAFIA E ESTATÍSTICA IBGE. Banco de Dados Agregados. Rio de Janeiro, 2005. Disponível em: $<$ http://www.ibge.gov.br>. Acesso em: 2 fev. 2006

KATZ, L. F; MEYER, B. D. The impact of the pontencial duration of unemployment benefits on the duration of unemployment. Journal of Public Economic, v. 41, n. 1, 1990.

KNIGTH, J.; LI, S. Unemployment duration and earnings of re-employed workers in urban China. China Economic Review, v. 17, p. 103-119, 2006.

KOENKER, R. Quantile tegression. Cambridge University Press, 2005.
KOENKER, R.; BASSETT, G.

Regression quantiles.

Econometrica, v. 46, n. 1, p. 33-50, Jan. 1978.

LAYARD, R.; NICKELL, S.; JACKMAN, R. Unemployment. Macroeconomic Performance and the Labour Market. Oxford University Press, 1991.

LJUNGQVIST, L.; SARGENT, T. The Europian Unemployment Dilemma. Working paper, 1997.

MALBOUISSON, C. S.; MENEZES, W. F. Duração do desemprego na Região Metropolitana de Salvador: mensuração e análise. Revista Econômica do Nordeste, Fortaleza, v. 35, n. 3, p. 315-338, jul. 2004

MENEZES FILHO, N. A.; PICHETTI, P. Os determinantes da duração do desemprego no Brasil metropolitano: 1984-1998. In: CHAHAD, J. P. Z.; MENEZES FILHO, N. A. (Orgs.). Mercado de trabalho no Brasil: salário, emprego e desemprego numa era de grandes mudanças. São Paulo: LTr, 2002. p. 55-79.

MORTENSEN, D. T. Job search, the duration of unemployement and the Phillips Curve. American Economic Review, v. 60, 1986 
MUKOYAMA, T:; SAHIN, A.

Why did the average duration of unemployment become so much longer?. FRB of New York Staff Report, n. 194, 1994.

OISON, M. The secular increase in European unemployment rates. European Economic Review, v. 39, p. 593-599, 1995.

OLIVEIRA, V. H.; CARVALHO, J. R. Salário de reserva e duração o desemprego no Brasil: uma análise com dados da pesquisa de padrão de vida do IBGE. Anais... ANPEC, 2006. Disponível em: <http:// www.anpec.org.br/encontro2006/ artigos/A06A036.pdf>.

Acesso em: 5 mar. 2007.

PENCAVEL, J.. Labor supply

of men: A survey.

In: ASHENFELTER, $\mathrm{O}$.

LAYARD, R. (Eds). The Handbook

of Labor Economics, Amsterdam:

Elsevier, 1986. v. 1.

PISSARIDES, C. A. Loss of skill during unemployment and the persistence of employment shocks. Quarterly Journal of Economics,

London, v. 107, n. 4, p. 1371-1391, Nov. 1992.

ROED, K.; RAAUM, O.; GOLDSTEIN, H. Does unemployment cause unemployment? Micro evidence from Norway. Applied Economics, London, v. 31, n. 10, p. 1207-1218, Oct. 1999.

VAN DEN BERG, Gerald J. Empirical inference with equilibrium search models of the labour market. Economic Journal, v. 109 , p. 283-306, 1999
ZYLBERSTAJN, H.; BALBINOTTO NETO, G

$\mathrm{O}$ uso repetido do seguro-desemprego no Brasil, 1986-1998: Teorias e evidências. Revista de Economia, v. 3, 2002.

$:$. . . . . . . . . . . . . . . .
E-mail de contado dos autores:
pauloaguiardomonte@gmail.com
ignacio.tavares@gmail.com
$\vdots$ marcialpbr@yahoo.com.br
$\vdots$ Artigo recebido em julho de 2007;
$\vdots$ aprovado em outubro de 2009. . . . . . . .

